\title{
COVID 19 e o fechamento da Ponte Internacional da Amizade
}

\author{
COVID 19 y el cierre del Puente de la Amistad Internacional \\ COVID 19 and the closing of the International Friendship Bridge
}

Milena Costa Mascarenhas ${ }^{1}$

Samuel Klauck ${ }^{2}$

\begin{abstract}
Resumo
O objetivo deste artigo é discutir a relação da covid-19, no período pandêmico de 2020, e os impactos com o fechamento da Ponte Internacional da Amizade, entre os meses de março e outubro, localizada sobre o rio Paraná na região binacional entre Foz do Iguaçu e Ciudad del Este. Para isso, apresenta-se a ponte como um local, historicamente, utilizado para práticas de diferentes manifestações públicas cuja tática adotada é o seu bloqueio, mas que, em 2020 viu-se fechada por uma determinação dos Estados Brasil e Paraguai, ocasionando um amplo movimento pela abertura da ponte devido sua importância nas áreas sociais e econômicas. A pesquisa baseia-se na análise de fontes jornalísticas, historiográficas e documentais.
\end{abstract}

Palavras-Chave: Pandemia; COVID 19; Ponte Internacional da Amizade; Foz do Iguaçu; Ciudad del Este.

\section{Resumen}

El propósito de este artículo es discutir la relación del covid-19, en el período pandémico de 2020, y los impactos con el cierre del Puente de la Amistad Internacional, entre los meses de marzo y octubre, ubicado sobre el río Paraná en la región binacional entre Foz do Iguaçu y Ciudad del Este. Para ello, el puente se presenta como un lugar, históricamente, utilizado para prácticas de diferentes manifestaciones públicas cuya táctica adoptada es su bloqueo, pero que, en 2020, fue cerrado por una determinación de los Estados Brasil y Paraguay, provocando una amplia movimiento para la apertura del puente debido a su importancia en el ámbito social y económico. La investigación se basa en el análisis de fuentes periodísticas, historiográficas y documentales.

Palabras claves: Pandemia; COVID 19; International Friendship Bridge; Foz do Iguaçu; Ciudad del Este.

\begin{abstract}
The purpose of this article is to discuss the relationship of covid-19, in the pandemic period of 2020, and the impacts with the closure of the International Friendship Bridge, between the months of March and October, located over the Paraná River in the binational region between Foz do Iguaçu and Ciudad del Este. For this, the bridge is presented as a place, historically, used for practices of different public manifestations whose adopted tactic is its blockade, but which, in 2020, was closed by a determination of the States Brazil and Paraguay, causing a wide movement for the opening of the bridge due to its importance in social and economic areas. The research is based on the analysis of journalistic, historiographic and documentary sources.
\end{abstract}

Keywords: Pandemic; COVID 19; Ponte Internacional da Amizade; Foz do Iguaçu; Ciudad del Este.

\footnotetext{
${ }^{1}$ Doutora em Sociedade, Cultura e Fronteira; Universidade Estadual do Oeste do Paraná; Foz do Iguaçu, Paraná, Brasil; milena.mk@gmail.com.
}

${ }^{2}$ Doutor em História; Universidade Estadual do Oeste do Paraná; Foz do Iguaçu, Paraná, Brasil; samuelk98@msn.com. 


\section{Introdução}

No dia 11 de março de 2020, a Organização Mundial da Saúde - OMS, caracterizou a covid-19 como uma pandemia, ou seja, o novo vírus estava mundialmente disseminado, com mais de 118 mil casos em 114 países e 4,2 mil pessoas tinham perdido a vida (mês/ano base: março de 2020). Desta forma, os países empreenderam diferentes ações para esse período pandêmico, no sentido de conter o vírus, proteger e tratar os pacientes.

Diante deste contexto, a Ponte Internacional da Amizade foi fechada, mantendo-se por 7 meses bloqueada. Os municípios de Ciudad del Este e Foz do Iguaçu foram afetados, em especial os setores do comércio e turismo.

A ponte muitas vezes fechada por manifestantes viu-se protagonizada nas manifestações para a sua reabertura.

\section{A Ponte Internacional da Amizade}

A Ponte Internacional da Amizade foi construída entre 1956 e 1965 ligando, sobre o rio Paraná, os municípios de Ciudad del Este, Paraguai e Foz do Iguaçu, Brasil. Até a inauguração em 1965, os transeuntes de ambos os lados realizavam a travessia por balsas, seja para visitarem amigos e parentes ou para comércio.

A Ponte da Amizade, não raro é eclipsada pelas grandes atrações turísticas ficando muitas vezes associada a um mal necessário, a um meio para alcançar o paraíso dos importados. A memória do ilícito é muito presente e é reforçada pela mídia, quando retratada como símbolo do medo, da insegurança e da anomia. Outras vezes é retratada como um símbolo da união e de integração regional. Em 2020, a Ponte da Amizade ganhou outra retratação, a de âncora econômica na região binacional.

O pesquisador Pierre Nora (1993) discorre sobre os lugares de memória: "são lugares, com efeito nos três sentidos da palavra, material, simbólico e funcional [...]". A ponte se encaixa nessas categorias, pois trata-se um lugar material, literalmente construído com ferro e concreto, também se trata de um lugar funcional servindo de trânsito para atender diversas demandas sociais e econômicas e por fim é um lugar simbólico onde é depositado significado cultural.

Uma ponte existe com o propósito de ligar e/ou unir, ou seja, é uma estrutura física que auxilia na transposição de algum obstáculo, cuja consequência é aproximar espaços. No caso da Ponte da Amizade, a conexão deu-se através da criação de passagem sobre o rio 
Paraná, tornando o acesso facilitado, no sentido de não mais depender exclusivamente do transporte aquático, mas de ampliar as possibilidades de travessia seja a pé, de bicicleta, de carro, de moto, de ônibus ou de caminhão.

Uma decorrência da criação da ponte é a centralização do trânsito de passagem, facilitando assim a vigilância e o controle. E constitui-se de um espaço extremamente movimentado, considerado o principal corredor logístico entre Brasil e Paraguai, no qual transitam cerca de 20 mil pedestres e 40 mil veículos por dia, segundo a pesquisa realizada pelo Centro Universitário Dinâmica das Cataratas - UDC ${ }^{3}$ (ano-base 2018). Circula-se diariamente pela ponte uma intensa quantidade de pessoas e veículos provenientes de diferentes países. Trata-se da principal ligação rodoviária entre o Brasil e o Paraguai, por onde, circula a maior parte dos produtos comercializados entre os dois países. Segundo dados da ACIFI, a ponte movimenta cerca de $\mathrm{R} \$ 12$ bilhões em exportações todos os anos (ano-base 2016) ${ }^{4}$.

Assim como a previsão do tempo, a informação sobre a ponte da Amizade é divulgada diariamente pelos meios de comunicação local pois trata-se de interesse geral. A importância econômica e social faz com que esse espaço receba tal visibilidade da mídia, cujo slogan é diariamente anunciado nos telejornais: "vamos ver como está o movimento na Ponte na Amizade", destacando a mobilidade de milhares de pessoas que percorrem este trajeto todos os dias.

A Ciudad del Este foi considerada entre 1995 e 1996 a terceira maior zona franca do mundo, ficando atrás de Miami e Hong Kong, movendo cifras equivalentes a três vezes o Produto Interno Bruto do país ${ }^{5}$. A cidade tornou-se a capital do departamento do Alto Paraná com uma população de aproximadamente 281.422 mil pessoas $^{6}$ (totalizando 21 distritos). Atualmente, é o segundo maior centro urbano do Paraguai, depois da capital Assunção.

Sendo referência de grande mobilidade na região binacional, a ponte, torna-se muitas vezes um alvo para manifestações, cuja principal tática adotada é o seu bloqueio, pois resulta em maior visibilidade e impacto de modo a pressionar os atores envolvidos em abrir

\footnotetext{
${ }^{3}$ Transitam pela ponte cerca de 20 mil pedestres e 40 mil veículos por dia, segundo a pesquisa realizada pela UDC. Centro Universitário Dinâmica das Cataratas. Pesquisa sobre o tráfego de veículos e pessoas que atravessam a Ponte Internacional da Amizade. Foz do Iguaçu, PR. 1 1 Edição, Junho, 2018.

${ }^{4}$ Segundo dados da ACIFI, a ponte movimenta cerca de R \$ 12 bilhões em exportações todos os anos (ano-base 2016). Disponível em: http://www.revistaacifi.com.br/edicao-12/revitalizada-ponte-da-amizade-conecta-odesenvolvimento-de-foz-do-iguacu/. Acesso em: 02 out. 2020.

${ }^{5}$ UltimaHora. Disponível em: <https://www.ultimahora.com/50-anos-historia-n81785.html>. Acesso em: 20 abr. 2020.

${ }^{6}$ DIRECCIÓN GENERAL DE ESTADÍSTICA, ENCUESTAS Y CENSOS. Atlas Demográfico del Paraguay 2012 (2016, p. 361).
} 
negociação sobre as demandas apresentadas em troca da retomada da fluidez do trânsito sobre o rio Paraná.

Em relação aos bloqueios realizados na ponte, foi realizada uma pesquisa, utilizando a ferramenta de busca do Google para localizar eventos jornalísticos que noticiavam os bloqueios provocados por protestos na Ponte da Amizade entre 2019 e início de 2020. Foram localizadas seis situações de bloqueio realizadas por manifestantes e em sua maioria protagonizados por paraguaios.

Tabela 1 - Bloqueios realizados na Ponte Internacional da Amizade

\begin{tabular}{|c|c|c|}
\hline DATA & FATO & REIVINDICAÇÃO \\
\hline $07 / 02 / 2019^{7}$ & Bloqueio de 5h da Ponte da Amizade & Destituição da prefeita Sandra McLeod Zacarias. \\
\hline $12 / 06 / 2019^{8}$ & $\begin{array}{l}\text { Protesto de comerciantes impediu a entrada ou } \\
\text { saída do Paraguai pela ponte. }\end{array}$ & $\begin{array}{l}\text { Reivindicação com o rigor na fiscalização e } \\
\text { apreensão de alimentos comprados em Foz do } \\
\text { Iguaçu. }\end{array}$ \\
\hline $23 / 07 / 2019^{9}$ & $\begin{array}{l}\text { Bloqueio em meia pista da Ponte da Amizade. O } \\
\text { protesto foi de trabalhadores taxistas. }\end{array}$ & $\begin{array}{l}\text { Os taxistas protestam contra o transporte realizado } \\
\text { por motoristas de aplicativos. }\end{array}$ \\
\hline $10 / 09 / 2019^{10}$ & $\begin{array}{l}\text { Os "passeros" (atravessam a fronteira para } \\
\text { buscar alimentos no Brasil, na Central de } \\
\text { Abastecimento do Paraná - Ceasa) paraguaios } \\
\text { bloqueiam parcialmente a Ponte da Amizade, em } \\
\text { protesto. }\end{array}$ & $\begin{array}{l}\text { Reivindicação da severa fiscalização na aduana } \\
\text { paraguaia e exigem a liberação total para passar } \\
\text { com os produtos. }\end{array}$ \\
\hline $14 / 09 / 2019^{11}$ & Bloqueios intermitentes na Ponte da Amizade. & $\begin{array}{l}\text { Pedem que o Congresso paraguaio abra um } \\
\text { processo de impeachment contra Marito e seu vice, } \\
\text { Hugo Velázques, após a assinatura de um acordo } \\
\text { bilateral com o governo brasileiro sobre o setor } \\
\text { energético. }\end{array}$ \\
\hline $16 / 09 / 2019^{12}$ & $\begin{array}{l}\text { Bloqueio de algumas horas da Ponte da } \\
\text { Amizade, organizado pelos policiais. }\end{array}$ & $\begin{array}{l}\text { São contrários a medida do governo federal que dá } \\
\text { poder de polícia ao Exército. }\end{array}$ \\
\hline
\end{tabular}

7 G1. Disponível em: https://g1.globo.com/pr/oeste-sudoeste/noticia/2019/02/07/apos-cinco-horasmanifestantes-liberam-transito-na-ponte-da-amizade.ghtml>. Acesso em: 02 out. 2020.

8 Paraná Portal. Protesto bloqueia Ponte da Amizade, no Oeste do Paraná. Disponível em: < https://paranaportal.uol.com.br/cidades/protesto-bloqueia-ponte-da-amizade/>. Acesso nov. 2020.

9 Naoviu. Fotos do dia: protesto dos taxistas paraguaios na Ponte da AmizadeDisponível em: https://www.naoviu.com.br/fotos-do-dia-protesto-dos-taxistas-paraguaios-na-ponte-da-amizade/>. Acesso nov. 2020.

${ }^{10}$ G1. Paraguaios fazem protesto na Ponte da Amizade e reclamam de fiscalização severa para passagem de alimentos. Disponível em: <https://g1.globo.com/pr/oeste-sudoeste/noticia/2019/09/10/paraguaios-fazemprotesto-na-ponte-da-amizade-e-reclamam-de-fiscalizacao-severa-para-passagem-de-alimentos.ghtml>. Acesso nov. 2020.

11 Radio Cultura Foz. Disponível em: https://www.radioculturafoz.com.br/2019/08/14/greve-geral-fechacomercio-no-paraguai-2/>. Acesso nov. 2020.

12 G1. Disponível em: https://g1.globo.com/pr/oeste-sudoeste/noticia/2019/09/16/contra-decisao-de-governoparaguaio-policiais-realizaram-protesto-na-ponte-internacional-da-amizade.ghtml>. Acesso nov. 2020. 
RELACult - Revista Latino-Americana de Estudos em Cultura e Sociedade

\begin{tabular}{|l|l|l|}
\hline $13 / 02 / 2020^{13}$ & $\begin{array}{l}\text { Motociclistas brasileiros fecham Ponte da } \\
\text { Amizade em protesto contra fiscalização } \\
\text { paraguaia. }\end{array}$ & $\begin{array}{l}\text { Afirmam que motos estão sendo apreendidas } \\
\text { mesmo com documentação regular. }\end{array}$ \\
\hline
\end{tabular}

Fonte: Tabela organizada pela autora.

O bloqueio da Ponte da Amizade ocorre com certa frequência. O protagonismo das manifestações é bastante diversificado, bem como suas causas de âmbito local ou nacional.

Em 2020, a Ponte da Amizade ficou bloqueada por 7 meses, por uma decisão dos Estados paraguaios e brasileiros como uma medida de segurança sanitária, conforme a descrições dos fatos abaixo.

\subsection{A Ponte Internacional da Amizade no período pandêmico de 2020}

No dia 18 de março de 2020, o presidente do Paraguai, Mario Abdo Benítez decretou o bloqueio da fronteira Paraguaia de acordo com o Plano Nacional de Resposta a Pandemia por coronavírus: "al anunciar el cierre del Puente de la Amistad al tránsito de personas, el presidente señaló que el Gobierno ha considerado la necesidad de tomar esta nueva decisión para fortalecer la política preventiva contra el coronavirus ${ }^{14 \%}$. Desta forma, o Paraguai em ação histórica fechou a Ponte Internacional da Amizade com o intuito de minimizar a propagação do novo coronavírus.

O maior receio do Estado Paraguaio era que a doença se espraiasse pelo país colapsando o já precário sistema de saúde, uma vez que o Brasil apresentava elevação nos casos. Essa percepção confirmou-se com o tempo, pois quase 90\% dos casos de COVID-19 no Paraguai foram importados do Brasil (mês/base: maio/2020) ${ }^{15}$ trazidos por imigrantes que viviam no Brasil e voltaram ao país de origem no período pandêmico. Além disso, o contrabando pelo rio Paraná fez aumentar os casos de contaminação em Ciudad del Este, tornando-se um epicentro da pandemia no país, no mês de agosto. O departamento com mais casos registrado era o Alto Paraná, cuja capital é Ciudad del Este, com 44,8\% (mês/base: agosto/2020) dos casos de covid-19, embora a região tenha $12 \%$ da população do país.

\footnotetext{
${ }^{13}$ Rádio Cultura Foz. Disponível em: https://www.radioculturafoz.com.br/2020/02/13/motociclistas-brasileirosfecham-ponte-da-amizade-em-protesto-contra-fiscalizacao-paraguaia/>. Acesso nov. 2020.

${ }^{14}$ Ministério das Relações Exteriores do Paraguai. Disponível em: https://www.mre.gov.py/index.php/noticiasde-embajadas-y-consulados/ejecutivo-dispone-cierre-al-transito-de-personas-en-puente-de-la-amistad-fronteracon-el-brasil. Acesso em: 28 abr. 2020.

15 G1. Disponível em: <https://g1.globo.com/mundo/noticia/2020/05/09/867percent-dos-casos-de-covid-19registrados-no-paraguai-na-1a-semana-de-maio-sao-procedentes-do-brasil.ghtml>. Acesso em: dez. 2020.
} 
No dia seguinte após o bloqueio do Paraguai, o Brasil publicou a portaria $\mathrm{n}^{\circ} 125$, dispondo a restrição excepcional e temporária de entrada no país de estrangeiros da América do $\mathrm{Sul}^{16}$ por rodovias ou via terrestres. No dia 27 de março, na portaria $\mathrm{n}^{\circ} 152^{17}$, o Brasil prorroga por mais 30 dias, acrescentando a restrição para estrangeiros de todas as nacionalidades.

O Paraguai empenhou-se em manter o bloqueio de suas fronteiras, ao contrário do Brasil $^{18}$, foi firme no propósito de restringir a entrada de estrangeiros e para isso, nas fronteiras terrestres a exemplo das fronteiras do Paraguai com as cidades sul-mato-grossenses, colocaram arames farpados e construíram valas para impedir a passagem de veículos ${ }^{19}$.

A situação instaurada no mundo, no início de 2020, foi análoga a uma situação de guerra, onde os países precisaram agir sob exceção. Desta forma, a fronteira foi uma parte essencial das estratégias de defesa territorial. Ratzel (apud FERRETI, 2014) inclusive, utiliza uma metáfora entre a mobilidade dos povos e a mobilidade de organismos biológicos interagindo com o meio em constante movimento:

Passando para o aspecto político da mobilidade das fronteiras, é Ratzel que observa o status geográfico particular da guerra, que "cola as fronteiras" e determina, no direito internacional, uma suspensão temporária dos direitos fronteiriços pois, normalmente, a guerra é a premissa de uma alteração das fronteiras políticas. Todavia, conforme ele, a guerra não é um motor em si, mas um processo derivado do estímulo natural dos povos por seu espaço vital - conceito controverso que, no entanto, não se confunde com as assertivas da geografia alemã do século XX (FERRETI, 2014, p.14).

\footnotetext{
${ }^{16}$ Art. $1^{\circ}$ Esta Portaria dispõe sobre a restrição excepcional e temporária de entrada no País, conforme o disposto no inciso VI do caput do art. $3^{\circ}$ da Lei ${ }^{\circ} 13.979$, de 6 de fevereiro de 2020, de estrangeiros oriundos dos seguintes países: I - República Argentina; II - Estado Plurinacional da Bolívia; III - República da Colômbia; IV República Francesa (Guiana Francesa); V - República Cooperativa da Guiana; VI - República do Paraguai; VII República do Peru; e VIII - República do Suriname. Disponível em: <http://www.in.gov.br/en/web/dou//portaria-n-125-de-19-de-marco-de-2020-248881224>. Acesso em: 19 jun. 2020.

${ }^{17}$ Secretaria Geral da Presidência da República. Disponível em: <http://www.in.gov.br/en/web/dou/-/portaria-n152-de-27-de-marco-de-2020-250060288>. Acesso em: 19 jun. 2020.

${ }^{18} \mathrm{O}$ presidente Jair Bolsonaro reiteradas vezes afirma que é a favor de manter as fronteiras abertas. Disponível em: <https://www.radioculturafoz.com.br/2020/04/17/presidente-jair-bolsonaro-defende-reabertura-da-fronteiracom-o-paraguai/>. Acesso em: 19 jun. 2020.

${ }^{19}$ G1. Disponível em: https://g1.globo.com/ms/mato-grosso-do-sul/noticia/2020/03/21/paraguaios-cavam-valaspara-impedir-que-brasileiros-entrem-no-pais-e-governo-decreta-isolamento-total.ghtml>. Acesso em: 19 jun. 2020.
} 


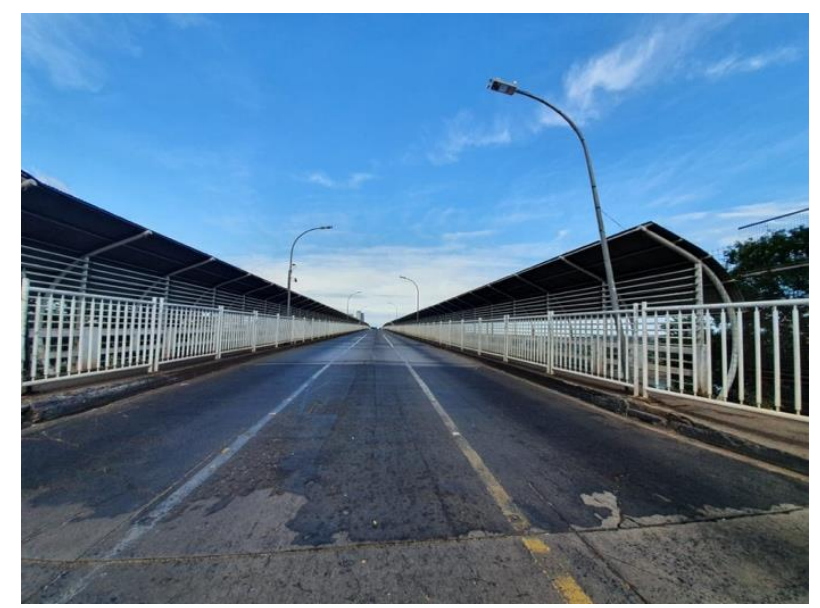

Foto 1 - Ponte Internacional da Amizade bloqueada. Foto de Renan Gouveia/RPC.

Fonte: RPC. Disponível em: <https://g1.globo.com/pr/oestesudoeste/noticia/2020/03/18/coronavirus-paraguai-fechaponte-da-amizade-em-foz-do-iguacu.ghtml>. Acesso em: 16 abr. 2020.

Desde 1965, data da inauguração, a ponte nunca tinha sido bloqueada pelo governo dos países, nem na maior obra de revitalização da ponte realizada entre 2015 e 2016. E, de repente, uma das fronteiras mais movimentadas da América Latina, foi esvaziada. A presença do Estado se tornou ostensivamente visível, que, em nome da segurança nacional e defesa interna, com o uso de suas atribuições, impediu temporariamente o livre trânsito até considerarem o país seguro da disseminação do novo coronavírus.

No dia 08 de abril de 2020 a Marinha paraguaia, cumprindo a determinação federal, instalou um portão de ferro na passarela pedestre, para bloquear a entrada de estrangeiros e paraguaios em Ciudad del Este.

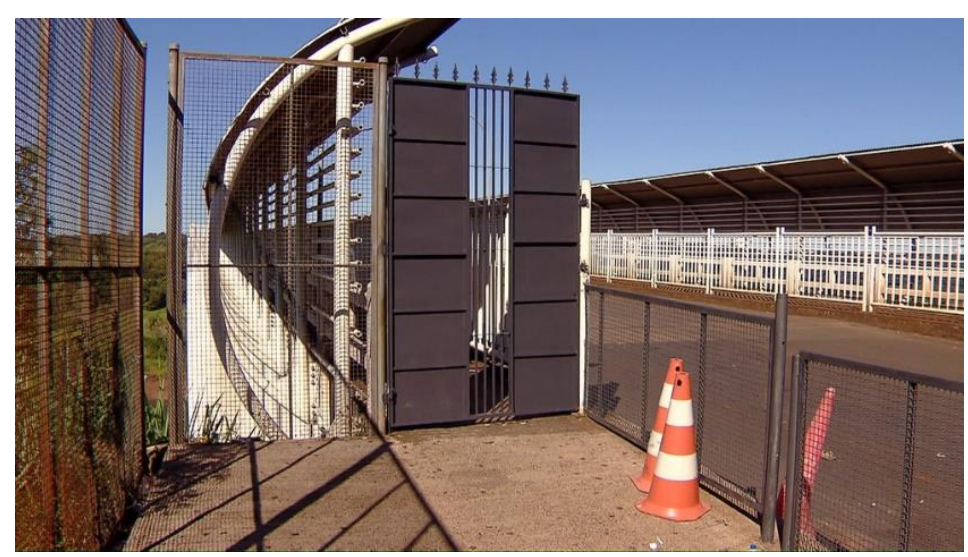

Foto 2 - Giovani Zanardi/RPC

Fonte: RPC. Disponível em: https://g1.globo.com/pr/oeste-sudoeste/noticia/2020/04/09/coronavirus-paraguaibloqueia-corredor-de-pedestres-na-ponte-da-amizade-com-barreira-de-ferro-na-fronteira-com-o-brasil.ghtml. Acesso 16 de abr. 2020. 
Os paraguaios permanecerem em quarentena na Ponte da Amizade, na ausência de estruturas provisórios, em uma espécie de "zona de espera" até receberem a liberação de acesso. Não podendo retornar ao Brasil em função de já terem dado baixa no passaporte e não podendo entrar em seu país, os "refugiados sanitários", ficaram na passarela da ponte, vulneráveis ao tempo, sem estrutura para comportá-los e sem liberdade de trânsito. Adultos e crianças ficaram dias aguardando a autorização para entrar no país.

“Estamos en una situación muy difícil acá, frio y mucha gente. Ahora vinieron más niños y mujeres, estamos como 600 por ahí, hace cuatro días que estamos acá. Recién llegaron tres o cuatro camiones llenos de paraguayos, estamos todos juntos acá como animales. Más ayuda que recibimos son de los brasileros, acá de Paraguay poco y los militares no quieren hablar con nosotros. Acá solo hay un baño y entre todos usamos ese, no hay ducha ni nada. El domingo a la noche los brasileros nos dieron una ducha”, señalón ${ }^{20}$.

Os refugiados sanitários tornaram-se os "indesejáveis", alocados em um espaço estreito, confinados e privados de benefícios básicos, à mercê da solidariedade dos brasileiros, pois, os paraguaios civis estavam impedidos de passar pela ponte e alcançar, caso quisessem ajudar, o grupo ectópico.

A decisão do governo de manter seus conterrâneos em uma ponte, sobre o rio Paraná, sem poder retornar ao Brasil e nem entrar no seu país materno, os colocou em um limbo fronteiriço, em uma situação de abandono às condições humanitárias mínimas, a exemplo, de instalação sanitária, alimentação, acomodação, tudo isso em um contexto de grave situação pandêmica. É o que o Fassin (2014, p. 5) chamará de biopolítica, ou seja, como a política lida com as vidas humanas, em especial com as vidas indesejadas, neste caso, os emigrantes. Em nome da "segurança da saúde pública", confinou-se os paraguaios privando-os do básico.

$\mathrm{O}$ argumento de que, os paraguaios provenientes do Brasil, seriam um risco ao país foi reforçado após aos resultados do exame desse grupo, demonstrando segundo Benetta $(2020)^{21}$, dos 370 casos de COVID-19 no Paraguai, 91 foram de paraguaios provenientes do Brasil, por isso, o país reforçou o controle de entrada para evitar a proliferação interna no país.

No dia 16 de abril de 2020, o Paraguai instalou na ponte, uma cabine de desinfecção para os compatriotas reingressar ao país. Segundo informações do jornal Última Hora “ $E l$ sistema cuenta con un sensor, rociadores y un tanque de 400 litros de productos

\footnotetext{
${ }^{20}$ NANDUTI. Paraguayos varados en el Puente de la Amistad denuncian que están todos juntos "como animales" Disponível em: <http://www.nanduti.com.py/2020/04/21/paraguayos-varados-puente-la-amistaddenuncian-estan-todos-juntos-animales/>. Acesso em: 10 mai. 2020.

21 BENETTA (2020). Disponível em: <https://www.h2foz.com.br/noticia/dos-370-casos-de-covid-19-noparaguai-91-sao-de-paraguaios-que-vieram-do-brasil>. Acesso em: 19 jun. 2020.
} 
desinfectantes, con capacidad de alrededor de 4.000 personas". Após o ingresso, as pessoas foram levadas para albergues temporários, para centros poliesportivos ou foram transportadas para Assunção para cumprir a quarentena obrigatória.
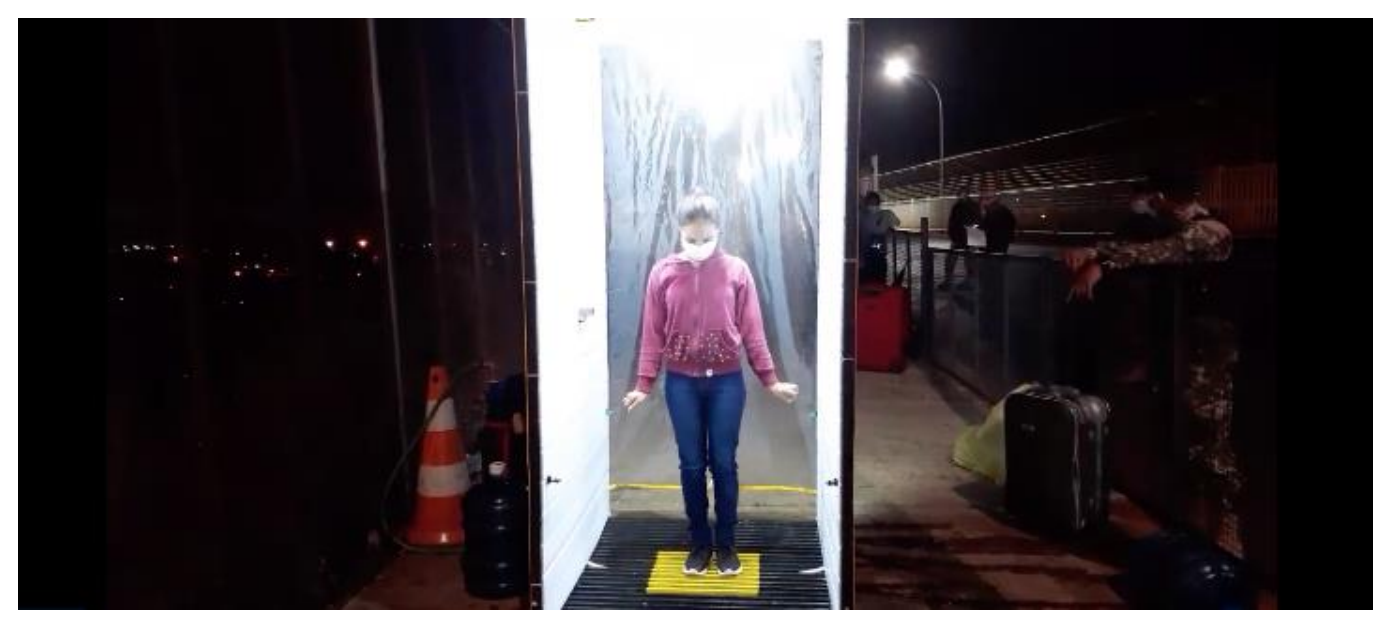

Foto 3 -A moça paraguaia passando pela cabine de desinfecção. Captura do vídeo.

Fonte: UltimaHora. Disponível em: <https://www.ultimahora.com/instalan-cabina-desinfeccion-paraguayos-queingresan-puente-la-amistad-n2880547.html>. Acesso em: 17 abr. 2020.

\subsection{O surgimento do vírus e o impacto mundial}

O mundo globalizado possibilita que algo ocorrido na China repercuta rapidamente (dada a distância) na movimentação dos transeuntes na Ponte da Amizade. Foi no dia 31 de dezembro de 2019, que a China anunciou o surgimento de 27 casos de pneumonia, na cidade de Wuhan. O alerta justificou-se, pois, tratava-se de um vírus de origem desconhecida.

Após estudos, os pesquisadores divulgaram a hipótese que o novo vírus teve origem em um mercado de frutos do mar e animais vivos na cidade de Wuhan. Em 7 de janeiro de 2020, um novo coronavírus $^{22}$, 2019-nCoV, chamado COVID-19 pela OMS em 11 de fevereiro, foi identificado como a causa. A rápida difusão do vírus pelo mundo fez com que a OMS declarasse em 11 de março, o COVID -19 uma pandemia global.

A maioria dos infectados, apresentava um quadro clínico com sintomas semelhantes aos de uma gripe comum, diferindo apenas no fato de, ao agravar o quadro clínico, evoluírem para uma pneumonia e em casos graves necessitando de $\mathrm{UTI}^{23}$. Sendo a transmissibilidade é

\footnotetext{
${ }^{22}$ Os três vírus são zoonóticos, com origem atribuída aos morcegos e passagem intermediária a outros mamíferos (civeta na SARS, camelo na MERS e, aparentemente, na COVID-19, pangolim).

${ }_{23}$ OTERO, PENÃ, David, et.al. ¿Preparados para el nuevo coronavirus? Disponível em: https://www.sciencedirect.com/science/article/pii/S0300289620300697?via\%3Dihub. Acesso em: 20 mar. 2020.
} 
muito alta, segundo estudos, tal vírus apresentou potencial para crescimento exponencial e sem tem remédio ou vacina disponível (mês/ano base: novembro/2020).

Inexistindo um agente antiviral, os países adotaram o chamado "Princípio da Ação Preventiva", ou seja, uma série de medidas públicas, a exemplo da conscientização da higienização das mãos com sabão e álcool em gel, o uso de máscaras nos locais públicos e o distanciamento social. Neste caso, para evitar o contato entre as pessoas, medidas mais ostensivas foram adotadas por diferentes países a exemplo de fechamento de fronteiras.

A História das epidemias está estritamente relacionada com a locomoção humana que transporta também micróbios, segundo Ujvari (2003) o trajeto seguido pelas epidemias era concordante com os percursos de deslocamento humano. Portanto, práticas de contenção foram adotadas no sentido de impedir a disseminação ou alastramento de doenças. $\mathrm{O}$ desconhecimento da causa da peste bubônica, fez com que em 1348, Veneza limitasse o trânsito comercial.

Em Veneza, ocorreu o pavor de a peste bubônica chegar nas embarcações procedentes do Mediterrâneo, e a administração urbana decidiu que todas elas permanecessem isoladas na baia por quarenta dias antes que seus ocupantes pudessem desembarcar - nascia assim a "quarentena" (UJVARI, 2003, p. 23).

Durante o avanço da febre amarela na América no final do século XIX, “as populações passaram a proibir a entrada de estrangeiros nas cidades, a destruir pontes e estradas de ferro que lhes davam acesso e a construir barreiras nas entradas" (UJVARI, 2003, p. 92).

Antes da COVID-19, ainda no Século XXI houve uma pandemia decretada pela OMS em abril de 2009, a gripe A H1N1. As medidas de contingenciamento foram tomadas em vários países do mundo, mas na ocasião, a recomendação de fechamento de fronteiras ou restrição ao movimento de pessoas, foi desencorajada pela $\mathrm{OMS}^{24}$.

Na pandemia de 2020, a OMS cria um documento de orientação aos países sobre medidas de implementação da quarentena, entendendo ser a forma mais eficaz, até o momento, para a prevenção e controle de infecções. A quarentena segundo a OMS ${ }^{25}$ "é a restrição de atividades ou a separação de pessoas que não estão doentes, mas que podem estar expostas a um agente ou doença infecciosa, com o objetivo monitorar seus sintomas e garantir o início precoce da detecção de casos". Já o isolamento é a separação das pessoas doentes ou infectadas das outras pessoas, impedindo a propagação ou disseminação da doença.

\footnotetext{
${ }^{24}$ BBC. Disponível em: https://www.bbc.com/portuguese/noticias/2009/06/090611_omspandemia_ac. Acesso 17 abr 2020.

${ }^{25}$ Who. Disponível em: https://www.who.int/publications-detail/considerations-for-quarantine-of-individuals-inthe-context-of-containment-for-coronavirus-disease-(covid-19). Acesso 17 abr 2020.
} 
O objetivo das medidas restritivas é atrasar o pico de contaminação para que os países possam organizar a infraestrutura hospitalar, o treinamento dos profissionais da saúde, a compra de equipamentos de proteção individuais - EPIs, bem como criar estratégias de controle e mapeamento dos doentes, tudo isso, até a vacina for efetivamente produzida, distribuída e aplicada.

\subsection{Movimentos para a Reabertura}

A Ponte da Amizade foi bloqueada e com essa ação, os movimentos para a sua reabertura, iniciaram, tanto no Brasil quanto no Paraguai, principalmente coordenados pelos setores mais atingidos como o do turismo, transportes e trabalhadores do em torno da ponte, a exemplo da Vila Portes no Brasil e Ciudad del Este no Paraguai.

Tabela 2 - Manifestações pela reabertura da Ponte Internacional da Amizade

\begin{tabular}{|l|l|l|}
\hline DATA & FATO & REIVINDICAÇÃO \\
\hline $20 / 05 / 2020^{26}$ & $\begin{array}{l}\text { Manifestação para reabertura da Ponte da } \\
\text { Amizade reúne mais de 100 veículos }\end{array}$ & Reivindicação pela abertura da Ponte da Amizade. \\
\hline $05 / 09 / 2020^{27}$ & $\begin{array}{l}\text { Comerciantes e trabalhares de Ciudad del Leste } \\
\text { organizaram uma passeata. }\end{array}$ & $\begin{array}{l}\text { Reivindicação pela abertura das fronteiras para } \\
\text { poder trabalhar. }\end{array}$ \\
\hline $22 / 09 / 2020^{28}$ & $\begin{array}{l}\text { O Conselho de Desenvolvimento Econômico e } \\
\text { Social de Foz do Iguaçu - } \\
\text { Codefoz emitiu um manifesto para reabertura da } \\
\text { ponte. }\end{array}$ & $\begin{array}{l}\text { O manifesto cita os problemas sociais e } \\
\text { econômicos decorrentes da restrição de acesso à } \\
\text { ponte e cobra do Governo do Paraguai } \\
\text { investimentos em estrutura assistencial e } \\
\text { reciprocidade à portaria do Brasil que permite livre } \\
\text { acesso às cidades-gêmeas, caso de Foz do Iguaçu e } \\
\text { Ciudad del Este, para fronteiriços. }\end{array}$ \\
\hline $22 / 09 / 2020^{29}$ & $\begin{array}{l}\text { Manifestação em Ciudad del Este anunciou a } \\
\text { grave crise econômica e social na região. }\end{array}$ & \begin{tabular}{l} 
Reivindicação pela abertura da Ponte da Amizade. \\
\hline
\end{tabular} \\
\hline
\end{tabular}

Fonte: Tabela organizada pela autora.

O impacto econômico é o principal argumento para a reabertura da ponte, segundo o deputado do Paraguai, Jorge Brítez ${ }^{30}$, cerca de $80 \%$ da população fronteiriça depende do comércio com o Brasil, que só em Ciudad del Este conta com 20.000 lojas que abastecem o

26 Portal da Cidade. Disponível em: <https://foz.portaldacidade.com/noticias/cidade/manifestacao-parareabertura-da-ponte-da-amizade-reune-mais-de-100-veiculos-4755>. Acesso em dez. 2020.

27 H2Foz. Disponível em: <https://www.h2foz.com.br/fronteira/trabalhadores-e-comerciantes-de-ciudad-deleste-fazem-manifestacao-pela-abertura-da-fronteira/>. Acesso em dez. 2020.

28 Portal da Cidade. Disponível em: <https://foz.portaldacidade.com/noticias/regiao/codefoz-lanca-manifestopela-reabertura-segura-da-ponte-internacional-da-amizade-1851>. Acesso em dez. 2020.

${ }^{29}$ G1. Disponível em: <https://gdia.com.br/noticia/cde-tera-manifestacao-permanente-pela-reabertura-da-ponteda-amizade>. Acesso em dez. 2020.

${ }^{30}$ Portal da cidade Foz do Iguaçu. Disponível em: <https://foz.portaldacidade.com/noticias/regiao/deputadoparaguaio-tira-camisa-para-pedir-reabertura-da-ponte-da-amizade-3815>. Acesso em dez. 2020. 
país com produtos importados. Com o fechamento da ponte, todo esse comércio paralisou suas atividades causando um grande rombo financeiro. Em Foz do Iguaçu, o impacto foi anunciado pelo Deputado Federal Vermelho, em agosto de 2020, no qual estimou 30 mil desempregados no município em função do fechamento da ponte ${ }^{31}$. O presidente da Associação Comercial e Empresarial de Foz do Iguaçu - ACIFI, Faisal Ismail estima a redução em 50\% na movimentação comercial na Vila Portes e no Jardim Jupira e em 30\% nos demais centros comerciais da cidade $^{32}$.

Conforme o jornal $\mathrm{ABC}^{33}$, ao entrevistar o analista Amílcar Ferreira, a estimativa é que o ano de 2020 retroceda em uma década com os indicadores de pobreza no Paraguai, em função do forte impacto da pandemia, colocando na linha da pobreza cerca de $30 \%$ da população, contra 23,5\% que era em 2019. O pleito de "abran el Puente de la Amistad, necesitamos tabajar ${ }^{34 \%,}$, coordenado pelo prefeito de Ciudad del Este, Miguel Prieto, passou a ser uma prioridade na região, portanto reuniões com autoridades brasileiras foram realizadas com o intuito de reivindicar a reabertura da ponte e o retorno do trabalho no município, extremamente afetado economicamente.

No debate promovido pela $\mathrm{ACIFI}^{35}$, com a participação do Conselho de Desenvolvimento Econômico e Social de Foz do Iguaçu - Codefoz, a Câmara do Comércio de Ciudad del Este - Codeleste e Câmara de Empresários de Ciudad del Este y Alto Paraná, números foram expostos em relação ao impacto do fechamento da Ponte da Amizade. Segundo a câmara do comércio de Ciudad del Este, cerca de 75 mil trabalhadores ficaram sem renda, destes, 20 mil são funcionários das lojas, 55 mil são microempreendedores ou informais. Estes, são números diretos, mas deve ser acrescentado o impacto indireto tanto Paraguai quanto no Brasil.

O Presidente do Conselho de Desenvolvimento Econômico e Social de Foz do Iguaçu, Mario Camargo, que trabalha com o comércio exterior diz que durante este período alcançou um recorde histórico do número de caminhões que atravessaram a Ponte da Amizade (em outubro de 2020 foram 25.727 caminhões), registrando a maior movimentação de cargas nos

\footnotetext{
31 Radio Cultura Foz. Disponível em: <https://www.radioculturafoz.com.br/2020/08/11/vermelho-pedereabertura-da-ponte-da-amizade-para-reativar-a-economia-na-camara/>. Acesso em dez. 2020.

32 H2Foz. Disponível em: <https://www.h2foz.com.br/fronteira/fechamento-da-ponte-da-amizade-reduzmovimento-no-comercio-de-foz/>. Acesso em dez. 2020.

33 ABC. Disponível em: <https://www.abc.com.py/nacionales/2020/09/08/estiman-retroceso-de-una-decada-enindice-de-pobreza/>. Acesso em dez. 2020.

${ }^{34}$ ABC. Disponível em: <https://www.abc.com.py/este/2020/08/26/abran-el-puente-de-la-amistad-necesitamostrabajar-insiste-el-intendente-prieto/>. Acesso em: dez. 2020.

35 Radio Cultura Foz. Disponível em: <https://www.radioculturafoz.com.br/2020/09/02/assista-ao-debatepromovido-pela-acifi-para-reabertura-da-ponte-da-amizade/>. Acesso em: dez. 2020.
} 
últimos quatro anos, evidenciando que o setor do agronegócio não foi afetado pela crise, inclusive crescendo em produtividade. O Presidente da ACIFI, Faisal Ismail, destaca impacto negativo maior nos setores de serviço, cuja principal fonte de renda era justamente a integração regional.

No dia 15 de outubro foi reaberta a Ponte da Amizade, em acordo com países Brasil e Paraguai. Um protocolo de medidas sanitárias foi implantado, limitando a entrada aos moradores de Foz do Iguaçu para o lado paraguaio e aos moradores de Ciudad del Este para o lado brasileiro.

Ao mesmo tempo que se aproxima do final do ano juntamente com datas como a Black Friday e Natal trazendo expectativas de retomada do movimento no comércio, o crescimento no número de infectados pelo novo coronavírus no Brasil e Paraguai traz insegurança do que pode acontecer na fronteira.

\section{Referências}

ABC. Estiman retroceso de una década em índice de pobreza. 8 set. 2020.

$<$ https://www.abc.com.py/nacionales/2020/09/08/estiman-retroceso-de-una-decada-en-indicede-pobreza/>. Acesso em: 20 dez. 2020.

ACIFI. Revitalizada, Ponte da Amizade conecta o desenvolvimento de Foz do Iguaçu. Edição 12, Ago 2016. Disponível em: http://www.revistaacifi.com.br/edicao-12/revitalizada-ponteda-amizade-conecta-o-desenvolvimento-de-foz-do-iguacu/. Acesso em: 02 out. 2020.

ALONSO, Tereza. Abran el Puente de la Amistad; necesitamos trabajar", insiste el intendente Prieto. ABC. 26 ago. 2020. Disponível em: <https://www.abc.com.py/este/2020/08/26/abranel-puente-de-la-amistad-necesitamos-trabajar-insiste-el-intendente-prieto/> e

BBC. OMS declara pandemia de gripe suína. 11 jun. 2009. Disponível em: https://www.bbc.com/portuguese/noticias/2009/06/090611_omspandemia_ac. Acesso em: 17 abr. 2020.

BENETTA, Claudio Dalla. Dos 370 casos de covid-19 no Paraguai, 91 são de paraguaios que vieram do Brasil. 3 de mai. de 2020. H2Foz. Disponível em:

<https://www.h2foz.com.br/noticia/dos-370-casos-de-covid-19-no-paraguai-91-sao-deparaguaios-que-vieram-do-brasil>. Acesso em: 19 jun. 2020.

BENETTA, Claudio Dalla. Trabalhadores e comerciantes de Ciudad del Este fazem manifestação pela abertura da fronteira. 5 set. 2020. H2Foz. Disponível em:

$<$ https://www.h2foz.com.br/fronteira/trabalhadores-e-comerciantes-de-ciudad-del-este-fazemmanifestacao-pela-abertura-da-fronteira/>. Acesso em dez. 2020.

CABELE, Josué. Assista ao debate promovido pela ACIFI para reabertura da Ponte da Amizade. Radio Cultura Foz. 2 set. 2020. Disponível em: 
<https://www.radioculturafoz.com.br/2020/09/02/assista-ao-debate-promovido-pela-acifipara-reabertura-da-ponte-da-amizade/>. Acesso em: dez. 2020.

CABELE, Josué. Motociclistas brasileiros fecham Ponte da Amizade em protesto contra fiscalização paraguaia. Rádio Cultura Foz. 13 fev. 2020. Disponível em:

<https://www.radioculturafoz.com.br/2020/02/13/motociclistas-brasileiros-fecham-ponte-daamizade-em-protesto-contra-fiscalizacao-paraguaia/>. Acesso em: nov. 2020.

CABELE, Josué. Vermelho pede reabertura da Ponte da Amizade para reativar a economia na Câmara. Radio Cultura Foz. 11 ago. 2020. Disponível em:

<https://www.radioculturafoz.com.br/2020/08/11/vermelho-pede-reabertura-da-ponte-daamizade-para-reativar-a-economia-na-camara/> . Acesso em: dez. 2020.

UDC - Centro Universitário Dinâmica das Cataratas. Pesquisa sobre o tráfego de veículos e pessoas que atravessam a Ponte Internacional da Amizade. Foz do Iguaçu, PR. Jun., 2018.

DANTE, Quadra. Greve geral fecha comércio no Paraguai. Radio Cultura Foz. 14 ago. 2019. Disponível em: 〈https://www.radioculturafoz.com.br/2019/08/14/greve-geral-fechacomercio-no-paraguai-2/>. Acesso em: nov. 2020.

DIRECCIÓN GENERAL DE ESTADÍSTICA, ENCUESTAS Y CENSOS. Atlas Demográfico del Paraguay 2012 (2016, p. 361).

FASSIN, Didier. Compaixão e Repressão: A Economia Moral das Políticas de Imigração na França, Ponto Urbe [Online], 15 | 2014, posto online no dia 30 dezembro 2014, consultado o 01 maio 2019. URL : http://journals.openedition.org/pontourbe/2467 ; DOI :

$10.4000 /$ pontourbe. 2467

FERREIRA, Wilson. 50 años de historia. UltimaHora. 5 dez. 2007. Disponível em: <https://www.ultimahora.com/50-anos-historia-n81785.html>. Acesso em: 20 abr. 2020.

FERRETTI, Federico. As origens da noção de "fronteiras móveis". Revista Continentes (UFRRJ), ano 3, n.4, 2014, p. 48-65.

NORA, Pierre. Entre Memória e História: a problemática dos lugares. Projeto História. São Paulo, dez. 1993

FREITAS, Ricardo e ANDRADA, Martim. G1. Paraguaios cavam valas para impedir que brasileiros entrem no país e governo decreta isolamento total. 21 mar. 2020. Disponível em: $<$ https://g1.globo.com/ms/mato-grosso-do-sul/noticia/2020/03/21/paraguaios-cavam-valaspara-impedir-que-brasileiros-entrem-no-pais-e-governo-decreta-isolamento-total.ghtml > Acesso em: 19 jun. 2020.

G1. 86,7\% dos casos de Covid-19 registrados no Paraguai na $1^{\text {a }}$ semana de maio são procedentes do Brasil. 9 mai. de 2020. Disponível em: <https://g1.globo.com/mundo/noticia/2020/05/09/867percent-dos-casos-de-covid-19registrados-no-paraguai-na-1a-semana-de-maio-sao-procedentes-do-brasil.ghtml>. Acesso em: dez. 2020. 
G1. Após cinco horas, manifestantes liberam trânsito na Ponte da Amizade. 7 fev. 2019.

Disponível em: https://g1.globo.com/pr/oeste-sudoeste/noticia/2019/02/07/apos-cinco-horasmanifestantes-liberam-transito-na-ponte-da-amizade.ghtml>. Acesso em: 02 out. 2020.

G1. Paraguaios fazem protesto na Ponte da Amizade e reclamam de fiscalização severa para passagem de alimentos. 10 set. 2019. Disponível em: 〈https://g1.globo.com/pr/oestesudoeste/noticia/2019/09/10/paraguaios-fazem-protesto-na-ponte-da-amizade-e-reclamam-defiscalizacao-severa-para-passagem-de-alimentos.ghtml>. Acesso em: nov. 2020.

GDia. CDE terá manifestação 'permanente' pela reabertura da ponte da Amizade. 22 set. 2020. Disponível em: <https://gdia.com.br/noticia/cde-tera-manifestacao-permanente-pelareabertura-da-ponte-da-amizade>. Acesso em: dez. 2020.

LANDIM, Marcos. Contra decisão de governo paraguaio, policiais realizaram protesto na Ponte Internacional da Amizade. 16 set. 2019. G1. Disponível em: <https://g1.globo.com/pr/oeste-sudoeste/noticia/2019/09/16/contra-decisao-de-governoparaguaio-policiais-realizaram-protesto-na-ponte-internacional-da-amizade.ghtml>. Acesso nov. 2020.

MINISTÉRIO das Relações Exteriores do Paraguai. Ejecutivo dispone cierre al tránsito de personas en Puente de la Amistad, frontera con el Brasil. 18 mar. 2020. Disponível em: $<$ https://www.mre.gov.py/index.php/noticias-de-embajadas-y-consulados/ejecutivo-disponecierre-al-transito-de-personas-en-puente-de-la-amistad-frontera-con-el-brasil>. Acesso em: 28 abr. 2020.

NANDUTI Diário Digital. Paraguayos varados en el Puente de la Amistad denuncian que están todos juntos “como animales”. 21 abr. 2020. Disponível em:

<http://www.nanduti.com.py/2020/04/21/paraguayos-varados-puente-la-amistad-denuncianestan-todos-juntos-animales/>. Acesso em: 10 mai. 2020.

NAOVIU. Fotos do dia: protesto dos taxistas paraguaios na Ponte da Amizade. 23 jul. 2019. Não Viu? um olhar sobre tudo. Disponível em: 〈https://www.naoviu.com.br/fotos-do-diaprotesto-dos-taxistas-paraguaios-na-ponte-da-amizade/>. Acesso em: 15 nov. 2020.

OTERO, David, et.al. ¿Preparados para el nuevo coronavirus? ScienceDirect. Vol. 56, p. 195-196, 2020. Disponível em:

<https://www.sciencedirect.com/science/article/pii/S0300289620300697?via\%3Dihub>. Acesso em: 20 mar. 2020.

PARANÁ PORTAL. Protesto bloqueia Ponte da Amizade, no Oeste do Paraná. 12 jun. 2019. Disponível em: <https://paranaportal.uol.com.br/cidades/protesto-bloqueia-ponte-daamizade/>. Acesso nov. 2020.

PARO, Denise. Fechamento da Ponte da Amizade reduz movimento no comércio de Foz. 5 out. 2020. H2Foz. Disponível em: 〈https://www.h2foz.com.br/fronteira/fechamento-daponte-da-amizade-reduz-movimento-no-comercio-de-foz/>. Acesso em: dez. 2020.

PORTAL DA CIDADE FOZ DO IGUAÇU. Deputado paraguaio tira camisa para pedir reabertura da Ponte da Amizade. 4 jun. 2020. Disponível em: 
<https://foz.portaldacidade.com/noticias/regiao/deputado-paraguaio-tira-camisa-para-pedirreabertura-da-ponte-da-amizade-3815>. Acesso em: dez. 2020.

PORTAL DA CIDADE FOZ DO IGUAÇU. Codefoz lança manifesto pela reabertura segura da Ponte Internacional da Amizade. 22 set. 2020. Disponível em:

<https://foz.portaldacidade.com/noticias/regiao/codefoz-lanca-manifesto-pela-reaberturasegura-da-ponte-internacional-da-amizade-1851>. Acesso em: dez. 2020.

PORTAL DA CIDADE FOZ DO IGUAÇU. Manifestação para reabertura da Ponte da Amizade reúne mais de 100 veículos. 20 mai. 2020. Disponível em:

<https://foz.portaldacidade.com/noticias/cidade/manifestacao-para-reabertura-da-ponte-daamizade-reune-mais-de-100-veiculos-4755>. Acesso em: dez. 2020.

RADIO CULTURA FOZ. Presidente Jair Bolsonaro defende reabertura da Fronteira com o Paraguai. 17 abr. 2020. Disponível em:

<https://www.radioculturafoz.com.br/2020/04/17/presidente-jair-bolsonaro-defendereabertura-da-fronteira-com-o-paraguai/>. Acesso em: 19 jun. 2020.

SECRETARIA-GERAL DA PRESIDÊNCIA DA REPÚBLICA. Diário Oficial da União. Portaria $n^{\circ}$ 152, de 27 de março de 2020. Disponível em: <http://www.in.gov.br/en/web/dou/|portaria-n-125-de-19-de-marco-de-2020-248881224>. Acesso em: 19 jun. 2020.

UJVARI, Stefan Cunha. A história e suas epidemias: a convivência do homem com os microrganismos. Rio de Janeiro: Senac Rio; São Paulo, Senac São Paulo, 2003. p. 71 a 102.

WORLD HEALTH ORGANIZATION. Considerations for quarantine of contacts of COVID19 cases. 19 ago. 2020. Disponível em: <https://www.who.int/publications-

detail/considerations-for-quarantine-of-individuals-in-the-context-of-containment-forcoronavirus-disease-(covid-19)>. Acesso em: 17 abr 2020. 